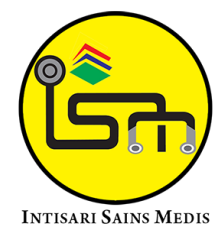

Published by Intisari Sains Medis

\section{Pengaruh dukungan sosial dan regulasi emosi terhadap kecenderungan depresi di Surabaya}

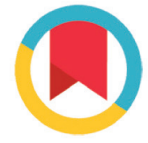

CrossMark

\author{
Harir Putriana', Elly Yuliandari Gunatirin ${ }^{2 *}$
}

\section{ABSTRACT}

Background: Cases of depression are increasing during the pandemic. It is necessary to understand the various things that can prevent the possibility of depression. A person's mental health condition is affected because they have to adjust to different needs and situations they experience, where their lives will never be the same again. This study aims to determine the effect of social support and emotional regulation on depression tendencies.

Methods: This research is a cross-sectional study with quantitative research using a survey. The measuring instrument used is the PHQ-9 to measure the tendency to depression, PSQ to see social support and ERQ to see the ability to manage emotions. There were 291 informants included in this study - selection of informants by purposive sampling method. Analysis of the data using regression analysis showed the social support model and emotional regulation of depression tendencies.

Results: The result showed a significant correlation in the social support and emotional regulation model on depression tendencies $(R=0918, p<0.01)$. The higher the emotional support and emotional regulation, the smaller the risk of experiencing depression. These two variables contribute $84 \%$ to the likelihood of depression.

Conclusion: Emotional support and emotion regulation are two significant variables to keep someone from experiencing depression. Efforts to maintain relationships and social communication, and emotional management still need to be done to maintain the risk of experiencing depression.

Keywords: Social Support, Emotion Regulation, Depression Tendencies.

Cite This Article: Putriana, H., Gunatirin, E.Y. 2021. Pengaruh dukungan sosial dan regulasi emosi terhadap kecenderungan depresi di Surabaya. Intisari Sains Medis 12(3): 862-867. D0I: 10.15562/ism.v12i3.1192

\title{
ABSTRAK
}

Pendahuluan: Kasus depresi semakin meningkat pada saat pandemi berlangsung. Masalah tersebut harus diberikan perhatian untuk mencegah kemungkinan timbulnya depresi. Kondisi kesehatan mental seseorang terpengaruh karena harus menyesuaikan berbagai kondisi dan situasi yang dialaminya, dimana kehidupan yang dijalani tidak akan pernah sama lagi. Penelitian ini bertujuan untuk mengetahui pengaruh dukungan sosial dan regulasi emosi terhadap kecenderungan depresi.

Metode: Penelitian ini merupakan penelitian dengan desain studi cross-sectional dengan menggunakan survey. Alat ukur yang digunakan adalah PHQ-9 untuk mengukur kecenderungan depresi, PSQ untuk melihat dukungan sosial dan ERQ untuk melihat kemampuan pengelolaan emosi. Responden yang disertakan dalam penelitian ini sejumlah 291 orang. Pemilihan responden dengan metode purposive sampling. Analisa data menggunakan analisis regresi yang diperoleh menunjukkan bahwa model dukungan sosial dan regulasi emosi terhadap kecenderungan depresi.

Hasil: Penelitian ini menunjukkan adanya korelasi yang signifikan pada model dukungan sosial dan regulasi emosi terhadap kecenderungan depresi $(\mathrm{R}=0.918, \mathrm{p}$ $<0.01$ ). Semakin tinggi dukungan emosi dan regulasi emosi maka semakin kecil risiko mengalami depresi. Kedua variabel ini memberikan sumbangan $84 \%$ terhadap kemungkinan depresi.

Simpulan: Dukungan emosi dan regulasi emosi merupakan dua variabel yang signifikan untuk menjaga seseorang dari kemungkinan mengalami depresi. Upaya untuk bisa menjaga relasi dan komunikasi sosial serta pengelolaan emosi tetap perlu dilakukan untuk menjaga risiko mengalami depresi.

Kata kunci: dukungan sosial, kecenderungan depresi, regulasi emosi.

Sitasi Artikel ini: Putriana, H., Gunatirin, E.Y. 2021. Pengaruh dukungan sosial dan regulasi emosi terhadap kecenderungan depresi di Surabaya. Intisari Sains Medis 12(3): 862-867. D0I: 10.15562/ism.v12i3.1192 


\section{PENDAHULUAN}

Wabah COVID-19 mulai menyebar di negara seluruh dunia semenjak awal tahun 2020. Hingga saat ini, COVID-19 telah menyebabkan angka 4,961,89 kematian. ${ }^{1}$ Adanya pandemi COVID-19 membuat penduduk di seluruh dunia mengalami perubahan. Faktor tersebut adalah krisis ekonomi, dan pembatasan sosial yang menghambat aktivitas masyarakat di berbagai bidang. ${ }^{1}$ Akibatnya, tidak sedikit penduduk di seluruh dunia mengalami tekanan karena tidak kuat menghadapi kondisi yang tidak nyaman. Ketidaknyamanan kondisi yang berlangsung secara terus menerus membuat seseorang berisiko mengalami masalah kesehatan mental. ${ }^{1,2}$ Beberapa faktor yang mendorong munculnya masalah kesehatan mental selamai pandemi seperti, rasa ketakutan dan ketidakpastian akan kondisi pandemi yang tidak dapat diprediksi kapan berakhir, stressor (kehilangan orang tercinta), kesulitan ekonomi, kekerasan dalam rumah tangga, hinga perubahan kebiasaan. $^{2}$

Menurut hasil survei yang dilakukan World Health Organization (WHO) terhadap 130 negara, menunjukkan adanya peningkatan untuk permintaan layanan kesehatan mental. ${ }^{3}$ Beberapa studi terdahulu menemukan bahwa pandemi COVID-19 berdampak negatif pada kesejahteraan psikologis seseorang. ${ }^{4}$ Selain itu, pandemi COVID-19 juga menyebabkan efek psikologis lain, seperti gangguan stress, stres pasca trauma dan depresi. ${ }^{4-6}$ Panchal et al melaporkan bahwa sebanyak $41 \%$ penduduk di US merasakan adanya gejala dari depresi dan kecemasan. ${ }^{7}$ Selain itu, sejumlah studi yang dilakukan menyatakan adanya peningkatan kasus kecemasan dan depresi. ${ }^{2}$ Kondisi kesehatan mental seseorang terpengaruh karena harus menyesuaikan berbagai kondisi dan situasi yang dialaminya, dimana kehidupan yang dijalani tidak akan pernah sama lagi. Penelitian lain juga menemukan bahwa gejala depresi yang dialami oleh penduduk berusia 18-39 tahun yang tinggal di US mengalami peningkatan tiga kali lebih tinggi dibandingkan sebelum adanya pandemi COVID-19. ${ }^{8}$ Beberapa faktor pendukung seseorang yang memiliki resiko mengalami depresi tinggi adalah sumber sosial dan ekonomi yang rendah, serta hal-hal lain yang dapat memicu stres. ${ }^{8}$

Kegiatan yang berhubungan dengan kesenangan, bergaul ataupun aktivitas produktif juga mengalami pembatasan. Bila kondisi pandemi memburuk, seseorang harus membatasi aktivitasnya dan membiarkan dirinya berdiam diri di rumah. Pemerintah menetapkan PSBB yang kemudian menjadi PPKM. Berbagai pengalaman atau situasi tidak menyenangkan dirasakan saat harus terpisah dari teman dan keluarga. Belum lagi berbagai pembatasan juga berdampak pada masalah ekonnomi seperti kehilangan pekerjaan. ${ }^{9}$ Penelitian menunjukkan adanya peningkatan kasus depresi dan kecemasan di masyarakat selama pandemic COVID-19.9

Sejumlah penelitian menunjukkan adanya stress dan gangguan psikologis lain yang semakin meningkat selama pandemi berlangsung. Penelitian menemukan adanya kondisi stres yang meningkat pada mahasiswa kedokteran. ${ }^{10}$ Hyunsuk et al,. mengungkapkan adanya kecemasan yang muncul selama masa isolasi atau karantina mandiri ataupun setelahnya. ${ }^{11}$ Perasaan yang timbul selama masa isolasi adalah marah dan cemas. Penelitian lain yang dilakukan Usher et al,. menunjukkan adanya hasil yang serupa. ${ }^{12}$ Xuerong et al,. melakukan meta-analisis pada 71 artikel jurnal yang telah dipublikasikan. ${ }^{13}$ Hasil penelitian yang dilakukan penunjukkan kasus kecemasan memiliki prevalensi $32,50 \%$, depresi sebesar $27,60 \%$, insomnia sebesar 30,30\% dan PTSD sebesar 16,76\%. Penelitian sejenis juga dilakukan pada 3166 kasus, dan 24 diantaranya dilakukan review. ${ }^{14}$ Berbagai studi yang dilakukan menunjukkan dampak negatif yang ditimbulkan dari isolasi sosial seperti halnya: post-traumatic stress symptoms, kebingungan dan kemarahan. Berdasarkan hal tersebut yang dianggap sebagai stressor adalah lamanya karantina, ketakutan pada infeksi, frustasi, kebosanan, kekurangan berbagai kebutuhan hidup, kehilangan penghasilan dan adanya stigma. Penelitian serupa juga dilakukan pada mahasiswa kedokteran. Hasil yang diperoleh menunjukkan bahwa 30,30\% mahasiswa mengalami stress selama masa belajar online berlangsung. ${ }^{10}$ Penelitian lain menunjukkan adanya kasus keinginan bunuh diri, depresi dan kecemasan yang terjadi selama masa karantina berlangsung. ${ }^{15}$ Penelitian-penelitian yang dilakukan tersebut menunjukkan adanya kerentanan yang menjadi risiko selama pandemi berlangsung, dimana salah satu kerentananan yang dimaksud adalah munculnya depresi. ${ }^{10,15}$

Kemampuan menghadapi kerentananan psikologis akan sangat dibutuhkan. Upaya untuk bisa memahami berbagai hal yang bisa meringankan kerentanan psikologis yang dialami akan sangat dibutuhkan. ${ }^{16}$ Orang perlu belajar untuk menyadari risk dan protective factor yang berperan bagi pengembangan diri. Keparahan gangguan mental yang dialami akan tergantung pada risk dan protective factor yang dimiliki seseorang dalam menghadapi situasi pandemik yang berlangsung. ${ }^{16}$ Dukungan sosial dan pengelolaan emosi akan memberikan kontribusi pada stress ataupun masalah psikologis yang dialami seseorang. Bila individu memiliki dukungan sosial dan regulasi emosi yang baik maka kemungkinan level stres juga akan lebih rendah. Penelitian yang dilakukan menunjukkan bahwa dukungan sosial akan memberikan pengaruh terhadap resiliesi terhadap stress. ${ }^{16}$ Dukungan sosial dapat diartikan sebagai kesempatan untuk mendapat akses interaksi dan semangat baik secara individu, kelompok maupun komunitas. Dukungan sosial akan bisa mengurangi kerentanan psikologis. ${ }^{16}$ Hasil serupa juga disampaikan penelitian lainnya mengenai hubungan dukungan sosial dan kesejahteraan mental (well being). ${ }^{17-19}$ Penelitian yang dilakukan Kang et al,. menunjukkan adanya hubungan antara sosial network dengan kesehatan mental. ${ }^{20}$ Penelitian-penelitian sejenis juga mengemukakan pentingnya dukungan sosial pada upaya mengatasi stress dan kesehatan mental. Dukungan sosial akan mempu membuat seseorang merasa dirinya berarti dan memiliki kekuatan menghadapi berbagai kendala dan tantangan yang dijumpai dalam hidup. ${ }^{20}$

Selain dukungan sosial, aspek lain yang juga berperan adalah regulasi emosi. Regulasi emosi merupakan sebuah proses yang kompleks, yang melibatkan inisiasi, penghambatan, atau modulasi respon 
atau perilaku seseorang secara emosional dalam menyikapi sebuah situasi. ${ }^{21}$ Emosi melibatkan transaksi person-situation yang membuat seseorang berusaha untuk menunjukkan perhatian (attention) akan situasi yang ada, memberikan makna, mengarahkan tujuan dan melakukan koordinasi diantara proses yang bersifat on going antara individu dan situasi yang ada. Regulasi emosi akan membuat seseorang lebih memiliki fleksibilitas dalam menghadapi beragam situasi yang dialami seseorang.

Selain dukungan sosial, sejumlah penelitian yang ada menunjukkan hubungan antara regulasi emosi dan kesehatan mental ataupun kemampuan sesorang dalam menghadapi beragam stres yang dialami. ${ }^{14,22-24}$ Penelitian yang dilakukan pada remaja menunjukkan hasil yang serupa. Studi pada 384 siswa remaja menunjukkan adanya korelasi yang signifikan antara kemampuan mengelola emosi dan penurunan tingkat kecemasan. ${ }^{2,4}$ Semakin baik pengelolaan emosi maka akan semakin kecil juga kemungkinan mengalami kecemasan. Penelitian ini bertujuan untuk mengetahui hubungan antara dukungan sosial, regulasi emosi dan dengan level stres, seberapa besar dukungan sosial dan regulasi emosi berperan untuk menurunkan depresi.

\section{METODE}

Penelitian ini menggunakan desain studi cross-sectional pendekatan kuantitatif dengan teknik survei. Jumlah sampel adalah 291 orang, berjenis kelamin lakilaki dan perempuan yang berusia antara 17 tahun hingga 43 tahun. Pengambilan data dilakukan dengan menggunakan purposive sampling. Pemilihan sampling didasarkan pada informan yang memiliki ciri berusia 17 tahun hingga 43 tahun. Pemilihan rentang usia tersebut didasarkan pada pertimbangan usia produktif. Sampel yang terlibat memiliki akses internet dan telah mengalami karantina PPKM selama lebih kurang 3 bulan. Kriteria ekslusi dari penelitian ini bila usia, masa karantina dan aksesibilitas internet tidak memenuhi persyaratan.

Skala yang digunakan untuk mengukur dukungan sosial adalah Perceived Sosial Support Questionnaire (PSQ) yang terdiri atas 12 item. Skala ini bertujuan untuk melihat persepsi individu terhadap dukungan yang diterima, baik dari teman, keluarga maupun orang-orang penting lainnya yang ada di lingkungan sekitarnya. Variabel regulasi emosi menggunakan skala Emotion Regulation Questionnaire (ERQ). Skala ini terdiri atas 10 item yang memiliki dua dimensi, yaitu (1) cognitive reappraisal dan (2) expressive suppression. Informan diminta untuk melakukan self report mengenai kondisi dirinya dalam mengelola emosi dengan menggunakan 7-point Likert-type scale.

Pengambilan data untuk kecenderungan depresi mengunakan Patient Health Questionnaire (PHQ-9). Skala ini merupakan quick depression assessment yang digunakan untuk melakukan screening kemungkinan mengalami depresi. Skala ini juga digunakan untuk mengetahui level depresi yang dimiliki sampel selama masa karantina. Analisa data penelitian menggunakan analisis regresi, dengan variabel independen adalah dukungan sosial dan regulasi emosi, serta variabel dependen adalah kecenderungan depresi.

\section{HASIL}

Data karaketristik demografis usia penelitian ini dapat dilihat pada Gambar 1. Penelitian ini melibatkan responden berusia 17 tahun hingga 43 tahun. Kelompok usia yang dimaksud adalah kelompok usia yang dianggap terdampak. Hasil menunjukkan bahwa usia 17-19 tahun merupakan kelompok usia terbanyak memiliki kecendrungan depresi dengan presentase sebesar $19 \%$. Kelompok usia terendah berada pada kelompok usia dengan rentangan 40-43 tahun. Pada Gambar 2, hasil penelitian ini menunjukkan jens kelamin perempuan memiliki risiko kecendrungan depresi sebesar $55 \%$ dengan 160 orang responden, sedangkan berjenis kelamin laki-laki sebanyak 131 orang responden (45\%).

Gambar 3 menunjukkan bahwa masalah yang paling banyak dialami adalah yang berhubungan dengan suasana hati. Secara rasional responden menyatakan bahwa responden memahami apa yang terjadi, namun secara emosi merasa terkejut dan membutuhkan waktu untuk bisa menata hidup dan emosinya untuk bisa mendapatkan kembali well being yang dimiliki. Adanya berbagai problem yang ada berisiko terhadap kemungkinan timbulnya depresi. Masalah keuangan, bosan, rasa malas, kekhawatiran akan masa depan serta berbagai batasan yang dialami selama masa PPKM meningkatkan risiko depresi.

Hasil analisis data (Tabel 1) menunjukkan adanya korelasi yang signifikan pada model dukungan sosial dan regulasi emosi terhadap kecenderungan depresi $\quad(R=0.918, \quad p$ $<0.01$ ). Dukungan sosial dan regulasi emosi secara bersama-sama memberikan kontribusi $84 \%$ terhadap kemungkinan depresi, dimana sekitar 16\% disebabkan faktor lainnya. Regulasi emosi dan dukungan sosial memberikan pengaruh

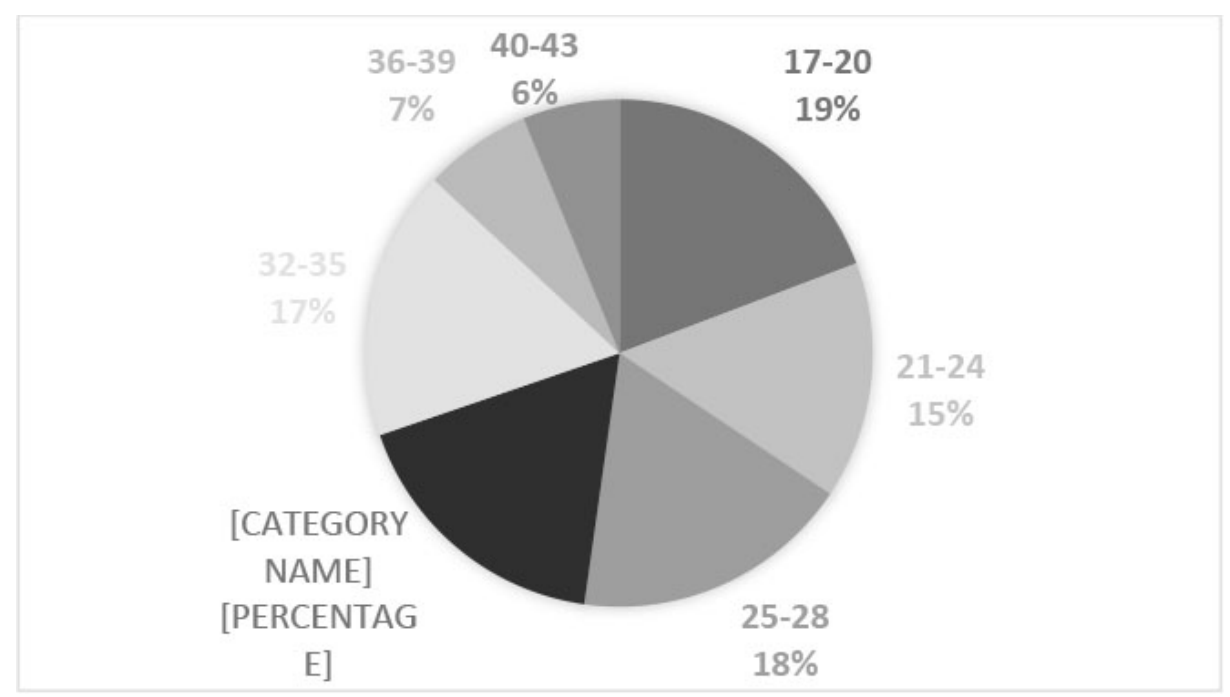

Gambar 1. Karakterisk demografi usia responden. 


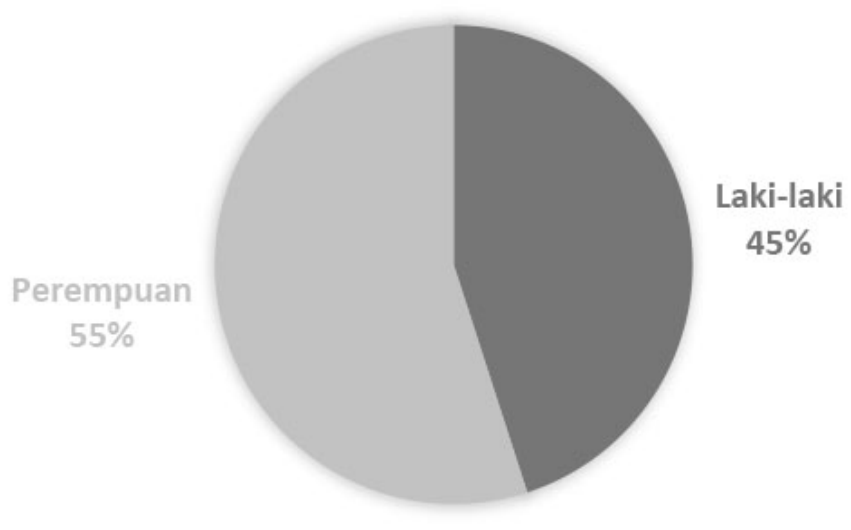

Gambar 2. Karakteristik demografi jenis kelamin responden.

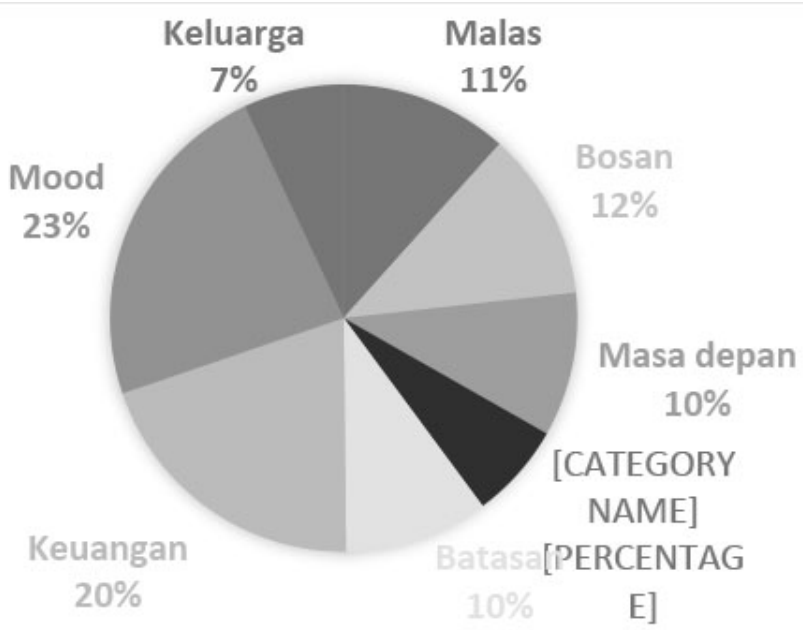

Gambar 3. Masalah yang dialami responden penelitian.

Tabel 1. Analisis bivariat pengaruh dukungan sosial dan regulasi emosi terhadap kecenderungan depresi.

\begin{tabular}{lccc}
\hline & Variabel & $\mathbf{R}$ & $\mathbf{p}$ \\
\hline Depresi (PHQ) & $\begin{array}{c}\text { Dukungan sosial (PSQ) } \\
\text { Regulasi emosi (ERQ) }\end{array}$ & 0,918 & 0,000 \\
\hline
\end{tabular}

Tabel 2. Analisis bivariat pengaruh dukungan sosial dan regulasi emosi sebagai prediktor terhadap timbulnya kecenderungan depresi.

\begin{tabular}{cccc} 
& Variabel & Mean Square & p \\
\hline \multirow{2}{*}{ Depresi (PHQ) } & Dukungan sosial (PSQ) & 3913 & 0,000 \\
& Regulasi emosi (ERQ) & 5.070 & \\
\hline
\end{tabular}

yang besar terhadap kemungkinan prevensi mengalami kecenderungan depresi. Keduanya secara bersama-sama memberikan pengaruh dengan presentase yang tinggi.

Dukungan sosial dan regulasi emosi bisa dijadikan prediktor terhadap kemungkinan timbulnya depresi dengan tingkat signifikansi masing-masing variabel adalah sebesar $p<0,001$. Hasil ini menunjukkan model ini bisa digunakan untuk memprediksi kecenderungan depresi (Tabel 2).

\section{PEMBAHASAN}

Dukungan sosial dan regulasi emosi merupakan dua variabel yang memberikan pengaruh signifikan pada kecenderungan depresi. Hal ini mengartikan bahwa individu yang mengalami karantina memiliki kecenderungan depresi yang rendah apabila memiliki dukungan sosial yang tinggi dan kemampuan melakukan regulasi emosi yang rendah. Hasil penelitian ini sejalan dengan berbagai penelitian yang dilakukan sebelumnya. ${ }^{16-20,22-25}$ Dukungan sosial dan regulasi emosi memberikan gambaran bagaimana faktor internal dalam diri individu (regulasi emosi) dan faktor eksternal (dukungan sosial) memberikan pengaruh yang signifikan pada kemungkinan timbulnya depresi.

Dukungan sosial merupakan bentuk konfirmasi pada seseorang bahwa dirinya bernilai dan memiliki arti. Berbagai kesulitan dan kesedihan yang dialami akan bisa diredam ketika ia merasa bahwa dirinya memiliki dukungan dan tempat untuk mengadu dan mengurangi berbagai beban yang dialami. Pada saat seseorang merasa bahwa dirinya memiliki teman maka akan memiliki keyakinan akan adanya bantuan dan pemahaman bahwa mereka tidak sendiri. Kesadaran bahwa dirinya tidak sendiri membuatnya merasa tenang dalam menghadapi beragam kendalam yang muncul. Regulasi emosi memberikan kesempatan pada individu untuk bisa mengelola emosinya. Ia akan memiliki kesadaran penuh akan perasaan atau kondisi emosinya. ${ }^{26}$

Individu yang memiliki kemampuan melakukan regulasi emosi, mampu menyadari emosi yang muncul dalam dirinya dan mengelolanya. Ia akan memiliki 
Tabel 3. Analisis multivariat pengaruh dukungan sosial dan regulasi emosi terhadap kecenderungan depresi.

\begin{tabular}{lcccc}
\hline & Variabel & \multicolumn{2}{c}{ Koefisien } & P \\
\cline { 3 - 4 } & & B & SE & \\
\hline \multirow{2}{*}{ Depresi (PHQ) } & & 27,597 & 0,455 & 0,000 \\
& Dukungan sosial (PSQ) & $-0,406$ & 0,044 & 0,000 \\
& Regulasi emosi (ERQ) & $-0,261$ & 0,015 & 0,000 \\
\hline
\end{tabular}

kesadaran mengenai kemungkinan meosi negatif yang muncul dan mengelolanya sehingga tidak berkembang lebih lanjut dalam bentuk kerentanan emosi. Emosi merupakan hasil dari penilaian dari peristiwa yang dialami seseorang (apptaisal of event). Penghayatan akan persitiwa yang dialami akan menimbulkan emosi positif ataupun negatif. Respon emosi yang diberikan merupakan pengolahan segenap pengalaman dan aspek fisiologis yang ada dalam diri seseorang. Respon yang diberikan melibatkan proses fisiologis, dan sosio-emosi yang muncul dalam perilaku. ${ }^{27,28}$ Pada penelitian ini menunjukkan bahwa dukungan sosial dan regulasi emosi secara bersama-sama merupakan cerminan penggunaan aspek internal dan eksternal untuk menilai situasi dan berespon pada situasi tersebut. Dalam hal ini terdapat kesadaran penuh untuk membuat seseorang akan respon psikologis yang dimilikinya dalam menghayati dan berespon pada situasi tersebut. ${ }^{29-31}$

\section{SIMPULAN}

Berdasarkan hasil penelitian ini bisa disimpulkan pentingnya dukungan sosial dan pengelolaan emosi untuk menjaga dan menghindari risiko mengalami depresi. Dukungan sosial merupakan rekognisi pada seseorang akan keberadaan dirinya dimana merupakan suatu pengakuan pada seseorang bahwa dirinya berharga. Di sisi lain pengelolaan emosi akan mampu membuat seseorang menjaga dirinya agar tetap bahagia dan menjaga emosinya diantara berbagai tekanan yang dialami. Menyimak hasil penelitian ini, maka penulis merekomendasikan agar network sosial, silaturahmi, komunikasi perlu terus dijaga dalam situasi sulit saat ini. Selain itu individu juga perlu diminta untuk distimulasi untuk belajar mengelola emosi agar bisa membuat diri lebih bahagia.

\section{KONTRIBUSI PENULIS}

Semua penulis berkontribusi dan memberikan peran seimbang dalam proses desain penelitian, pengambilan data, analisis maupun penulisan.

Penulis menyatakan tidak ada konflik kepentingan dalam penulisan.

\section{FUNDING}

Keseluruhan pembiayaan pada penelitian ini ditanggung sepenuhnya oleh penulis.

\section{UCAPAN TERIMAKASIH}

Ucapan terimakasih disampaikan kepada para asisten yang telah membantu penelitian dan seluruh responden yang terlibat dalam penelitian ini.

\section{DAFTAR PUSTAKA}

1. Kodvanj I, Homolak J, Virag D, Trkulja V. World Health Organization (WHO) COVID-19 Database: Who Needs It? [Internet]. MDPI AG; 2020. Available from: http://dx.doi. org/10.20944/preprints202007.0051.v2

2. Pedrosa AL, Bitencourt L, Fróes ACF, Cazumbá MLB, Campos RGB, de Brito SBCS, et al. Emotional, Behavioral, and Psychological Impact of the COVID-19 Pandemic. Front Psychol. 2020;11:566212. Available from: https://pubmed.ncbi.nlm.nih.gov/33117234

3. World Health Organization. Covid-19 Disrupting Mental Health Services in Most Countries [Internet]. COVID-19 and Wellbeing. WHO; 2020. Available from: https:// www.who.int/news/item/05-10-2020-covid19-disrupting-mental-health-services-in-mostcountries-who-survey

4. Alnazly E, Khraisat OM, Al-Bashaireh AM, Bryant CL. Anxiety, depression, stress, fear and social support during COVID-19 pandemic among Jordanian healthcare workers. PLoS One. 2021;16(3):e0247679-e0247679. Available from: https://pubmed.ncbi.nlm.nih. gov/33711026

5. Maunder R. The experience of the 2003 SARS outbreak as a traumatic stress among

\section{KONFLIK KEPENTINGAN}

frontline healthcare workers in Toronto: lessons learned. Philos Trans R Soc Lond B Biol Sci. 2004;359(1447):1117-25. Available from: https://pubmed.ncbi.nlm.nih.gov/15306398

6. Bisson JI, Tavakoly B, Witteveen AB, Ajdukovic $D$, Jehel L, Johansen VJ, et al. TENTS guidelines: development of post-disaster psychosocial care guidelines through a Delphi process. Br J Psychiatry. 2010;196(1):69-74. Available from: http://dx.doi.org/10.1192/bjp.bp.109.066266

7. Nirmita Panchal, Rabah Kamal, Cynthia Cox RG. The Implications of COVID-19 for Mental Health and Substance Use [Internet]. KFF; 2021. Available from: https://www.kff. org/coronavirus-covid-19/issue-brief/theimplications-of-covid-19-for-mental-healthand-substance-use/

8. Ettman CK, Abdalla SM, Cohen GH, Sampson L, Vivier PM, Galea S. Prevalence of Depression Symptoms in US Adults Before and During the COVID-19 Pandemic. JAMA Netw open. 2020;3(9):e2019686-e2019686. Available from: https://pubmed.ncbi.nlm.nih.gov/32876685

9. Basheti IA, Mhaidat QN, Mhaidat HN. Prevalence of anxiety and depression during COVID-19 pandemic among healthcare students in Jordan and its effect on their learning process: A national survey. PLoS One. 2021;16(4):e0249716-e0249716. Available from: https://pubmed.ncbi.nlm.nih. gov/33819301

10. Abdulghani HM, Sattar K, Ahmad T, Akram A. Association of COVID-19 Pandemic with undergraduate Medical Students' Perceived Stress and Coping. Psychol Res Behav Manag. 2020;13:871-81. Available from: https:// pubmed.ncbi.nlm.nih.gov/33154682

11. Jeong H, Yim HW, Song Y-J, Ki M, Min J-A, Cho J, et al. Mental health status of people isolated due to Middle East Respiratory Syndrome. Epidemiol Health. 2016;38:e2016048e2016048. Available from: https://pubmed.ncbi. nlm.nih.gov/28196409

12. Usher K, Bhullar N, Jackson D. Life in the pandemic: Social isolation and mental health. J Clin Nurs. 2020;29(15-16):2756-7. Available from: http://dx.doi.org/10.1111/jocn.15290

13. Liu X, Zhu M, Zhang R, Zhang J, Zhang C, Liu P, et al. Public mental health problems during COVID-19 pandemic: a large-scale metaanalysis of the evidence. Transl Psychiatry. 2021;11(1):384. Available from: https:// pubmed.ncbi.nlm.nih.gov/34244469

14. Myruski S, Denefrio S, Dennis-Tiwary TA. Stress and Emotion Regulation. In: The Oxford Handbook of Stress and Mental Health. Oxford University Press; 2018. p. 414-34. Available from: http://dx.doi.org/10.1093/ oxfordhb/9780190681777.013.19

15. Wathelet M, Duhem S, Vaiva G, Baubet T, Habran E, Veerapa E, et al. Factors Associated With Mental Health Disorders Among University Students in France Confined During the COVID-19 Pandemic. JAMA Netw open. 2020;3(10):e2025591-e2025591. Available from: https://pubmed.ncbi.nlm.nih. gov/33095252 
16. Ozbay F, Fitterling H, Charney D, Southwick S. Social support and resilience to stress across the life span: A neurobiologic framework. Curr Psychiatry Rep. 2008;10(4):304-10. Available from: http://dx.doi.org/10.1007/s11920-0080049-7

17. Cohen S, Wills TA. Stress, social support, and the buffering hypothesis. Psychol Bull. 1985;98(2):310-57. Available from: http:// dx.doi.org/10.1037/0033-2909.98.2.310

18. Wang X, Cai L, Qian J, Peng J. Social support moderates stress effects on depression. Int J Ment Health Syst. 2014;8(1):41. Available from: https://pubmed.ncbi.nlm.nih.gov/25422673

19. Thoits PA. Perceived Social Support and the Voluntary, Mixed, or Pressured Use of Mental Health Services. Soc Ment Health. 2011;1(1):4-19. Available from: http://dx.doi. org $/ 10.1177 / 2156869310392793$

20. Kang SH, Wallace NT, Hyun JK, Morris A, Coffman J, Bloom JR. Social Networks and Their Relationship to Mental Health Service Use and Expenditures Among Medicaid Beneficiaries. Psychiatr Serv. 2007;58(5):68995. Available from: http://dx.doi.org/10.1176/ ps.2007.58.5.689

21. Trueba AF, Pluck G. Social Support Is Related to the Use of Adaptive Emotional Regulation Strategies in Ecuadorian Adolescents in Foster Care. Psych. 2021;3(2):39-47. Available from: http://dx.doi.org/10.3390/psych3020005
22. Cloitre M, Miranda R, Stovall-McClough KC, Han H. Beyond PTSD: Emotion regulation and interpersonal problems as predictors of functional impairment in survivors of childhood abuse. Behav Ther. 2005;36(2):11924. Available from: http://dx.doi.org/10.1016/ s0005-7894(05)80060-7

23. Cole PM, Martin SE, Dennis TA. Emotion Regulation as a Scientific Construct: Methodological Challenges and Directions for Child Development Research. Child Dev. 2004;75(2):317-33. Available from: http:// dx.doi.org/10.1111/j.1467-8624.2004.00673.x

24. Evans GW, Kim P. Childhood Poverty, Chronic Stress, Self-Regulation, and Coping. Child Dev Perspect. 2012;7(1):43-8. Available from: http://dx.doi.org/10.1111/cdep.12013

25. Olstad R, Sexton H, Søgaard AJ. The Finnmark study. Social support, social network and mental distress in a prospective population study. Soc Psychiatry Psychiatr Epidemiol. 1999;34(10):519-25. Available from: http:// dx.doi.org/10.1007/s001270050170

26. Pulkkinen, L., Kaprio, J., \& Rose RJ. Socioemotional Development and Health From Adolescence to Adulthood [Internet]. Cambridge University Press; 2006. Available from: http://dx.doi.org/10.1017/ cbo9780511499784

27. Sheppes G, Gross JJ. Emotion Regulation Effectiveness: What Works When. In:
Handbook of Psychology, Second Edition. John Wiley \& Sons, Inc.; 2012. Available from: http:// dx.doi.org/10.1002/9781118133880.hop205018

28. Gross JJ, John OP. Individual differences in two emotion regulation processes: Implications for affect, relationships, and well-being. J Pers Soc Psychol. 2003;85(2):348-62. Available from: http://dx.doi.org/10.1037/0022-3514.85.2.348

29. Brooks SK, Webster RK, Smith LE, Woodland L, Wessely S, Greenberg N, et al. The psychological impact of quarantine and how to reduce it: rapid review of the evidence. Lancet (London, England). 2020/02/26. 2020;395(10227):91220. Available from: https://pubmed.ncbi.nlm. nih.gov/32112714

30. Butler EA, Egloff B, Wlhelm FH, Smith NC, Erickson EA, Gross JJ. The social consequences of expressive suppression. Emotion. 2003;3(1):48-67. Available from: http://dx.doi. org/10.1037/1528-3542.3.1.48

31. Nyklíček I, Vingerhoets A, Zeelenberg M. Emotion Regulation and Well-Being: A View from Different Angles [Internet]. Emotion Regulation and Well-Being. Springer New York; 2010. p. 1-9. Available from: http://dx.doi. org/10.1007/978-1-4419-6953-8_1

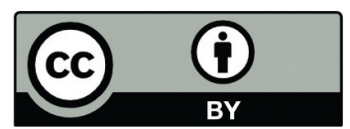

This work is licensed under a Creative Commons Attribution 